\title{
PLASTIC / NYLON WASTE POLLUTION AND DISPOSAL IN OYO STATE, NIGERIA
}

\author{
Bolaji K.A., Kabir G.B., Adebayo D.O., Oguntoye T.O. \\ Forestry Research Institute of Nigeria, Ibadan, Nigeria \\ E-mail: tunjikofoworola@yahoo.com
}

\begin{abstract}
This study examined the effect of plastic/nylon pollution, the disposal method and the factors influencing the methods of disposal in Oyo state. This study was conducted in eleven local government areas (LGA) of Oyo states using structured questionnaire with five hundred respondents purposively selected but 454 questionnaires were valid for the research analysis. The analytical tools used were descriptive statistics (such as percentage and frequency) and multinomial regression model. Majority $(81 \%)$ of the respondents were married, about $88.6 \%$ of the respondents were educated. Most $(84 \%)$ of the sampled households had a family size of between 1 and 5 with almost $60 \%$ of the respondents earning between $\$ 10,000-\$ 50,000$. The study observed that $54 \%$ of the respondents' choice of plastic and nylon disposal methods was time savings, about $86 \%$ had no difficult in disposing their waste, $29.5 \%$ of the respondents stated that plastic and nylon waste disposal block water ways. The factors influencing plastic/nylon disposal were waste collectors $(p<0.01)$, House ownership $(p<0.05)$ and educational status $(p<0.05)$. The Negelkerke $R^{2}$ indicates that $49 \%$ of the variation in the factors influencing plastic/nylon disposal is explained by the model. It is therefore recommended that more awareness should be made about plastic/nylon pollution and proper disposal. Then alternative packaging materials and reuse of plastic/nylon should be encouraged due to the difficulty in disposal.
\end{abstract}

\section{KEY WORDS}

Disposal, management, nylon, plastic, pollution, waste.

Plastic waste management has become an issue of increasing global concern as urban populations continue to rise and consumption patterns change. Environmental concern caused by inadequate plastic waste management as well as the steps to combat global warming promotes actions toward a sustainable management of plastic fraction of the waste. According to Livni (2019), 8million tons of plastic from all around the world flows into the ocean yearly to create devastating effect to the health of the ocean and the sea life. Plastics pollution was first found in the ocean in the 1970s and it is now becoming such a problem that it will outnumber fish by 2050 (Earth Day, 2018).

In Nigeria, plastic is a cheap packaging material with no usage restriction imposed on the production sector (Kadafa et al., 2017). They are used for packaging water, drinks, foods, beverages, chemicals, electronics and other items, it have been identified as veritable tool to enhance the value of a product and projection of its identity (Alade, 2017). However, fifty percent of the plastic products fall within the disposable products category since they are single-use plastic products and packaging materials (Kehinde et al., 2020). Most plastics and nylons waste are not disposed properly for considerable processing, recovery and standard disposal through recycling centers, incinerators or landfills. These wastes constitute nuisance around, that are inaccessible for waste collection and hence terminating the possibility of recovery/recycling. A good example of plastic/nylon waste is the pure water sachets, which contribute so much menace in the society. Due to its affordability, about 60 million used pure water sachets are disposed everyday across the country, implying that more than $65 \%$ of individuals drink pure water (Babatunde and Biala, 2010), let alone bottle water and others. These nylon and plastic wastes are indiscriminately dumped in drainages, gutters, canals and the streets. People litter the roads with no civic concern in Nigeria. They end up blocking flow of water in drainages thereby causing flooding. With many other cities in the urban 
developing world, cities in Nigeria are faced with the twin problems of population increases and rapid expansion.

Plastics/nylon wastes are abundantly found littering most areas in Oyo state, especially Ibadan the state capital, thus constituting an environmental problem blocking waterways, open lands, streets, filling up gutter and storm drains all over the city, especially the suburbs (Kadafa et al., 2017). Due to the commercial activities in the state, the quantity of waste generated is in direct proportion to population size- as population increase accompanied by increased waste generation. Population growth and higher standards of living has always affected waste generation, collection and invariably disposal. This has impacted negatively on both the environment and waste generation in Oyo state (Obayelu, 2013).

Waste is defined as any unavoidable material resulting from domestic activity or industrial operation for which there is no economic demand and which must be disposed off (Sridhar and Hammed, 2014). In other words, there is no precise word for waste but the usage is that "a material waiting to be re-used" is a waste. There are a variety of wastes, liquid or solid, emanating from human (domestic), agricultural or industrial activities (neither domestic nor hazardous). The markets generate a variety of wastes, for example, corn cobs, vegetable wastes, plastic/nylon packaging materials, etc. The household wastes also contain other materials such as paper, glass, metal, plastic, and other non-biodegradable materials. Some of them are excellent raw materials for various industries in the country. All these wastes contain a lot of valuable resources in the form of nitrogen, phosphorus, potassium and other chemicals which are useful (Hammed et al., 2011). However, organic waste pose a lesser danger to the environment as it can easily decompose; waste nylons and plastics pose serious environmental issues and nuisance to the environment. They are nonbiodegradable. It is estimated that it takes between 30 to 40 years for a nylon fabric to decompose (Delaney, 2013). This reduces water infiltration into the soil, land degradation, and can also make landfill site to fill up quickly (lbrahim et al., 2020). Burning of waste nylon and plastic bottles can cause air pollution which releases poisonous gases such as carbon monoxide, furans and dioxins are released to the air (Kehinde et al., 2020). They can endanger public health, destroy the ozone layer and contribute to global warming, thus the challenges of properly discarding them (Earth Day, 2018). There is therefore an urgent need to plan for the disposal of this synthetic products, implants etc which have completed their shelf life and to examine the factors which influence their methods of disposal. The challenges faced by the households in disposing this unavoidable waste need to be examined and studied in order to solve the problems arising there from. The issue actually is how the households will be able to dispose their plastic waste sustainably.

\section{METHODS OF RESEARCH}

The study was conducted in Oyo State, Southwestern part of Nigeria between Latitudes $2^{\circ} 38^{1}$ and $4^{0} 35^{1}$ east and has a total population of 5,591,589 (NPC, 2012). There are 33 local government areas in the state. It is bordered in the north by Kwara State, east by Osun State and the south by Ogun states. In the west, it is bordered by Ogun state and by the Republic of Benin. The state has an annual rainfall of between $1000 \mathrm{~mm}$ and $1400 \mathrm{~mm}$ and has a vast area of fertile land that is suitable for the production of arable crops such as the vegetables, yam, cassava, cowpea, tomatoes, maize and perennial crops such as cocoa, locust bean, Shea nut, Cashew etc. Farming in the state is largely traditional and small scale relying on manual labours that involve the use of cutlasses and hoes (Ademola et al., 2012).

This empirical study was conducted in eleven local government areas (LGA) of Oyo states using structured questionnaire. Five hundred and fifty respondents were interviewed with fifty respondents purposively selected in each local government areas due to abundant availability of disposed plastic /nylon in the environments. The survey came up with four hundred and fifty four questionnaires being valid for the research analysis. The selected LGA were Oluyole, Ibadan Southwest, Ido, Lagelu, Atiba, Owode, Ibadan North, Ibadan Northeast, Ogbomosho North, Ogbomoso South and Orire Local Government areas. 
Descriptive tools such as percentage and frequency distribution were used in the analysis with Multinomial logit Model.

Multinomial logit model assume response counts at each level of covariate combination. The benefit of using multinomial logit model is that it models the odds of each category relative to a baseline category as a function of covariate. The variation in the values of the dependent variable that is explained by the independent variables cannot be measured directly in logistic regression models, as it can be in multiple linear regression ones with $\mathrm{R}^{2}$. However, the pseudo $\mathrm{r}$-square statistics can provide an indication of explained variation in the values of the dependent variable, similar to the $R^{2}$ in multiple linear regression models. The null hypothesis that the model adequately fits the data can be examined by the Pearson and Deviance tests in the Goodness-of-fit part.

\section{RESULTS AND DISCUSSION}

Table 1 reflects the socioeconomic characteristics of the respondent household. It was found that majority $(69.6 \%)$ of the respondents were females. This is because culturally, females visit markets more to buy household needs, especially the groceries. Many $(81.1 \%)$ of the respondents were married, about $88.6 \%$ of the respondents were educated which implies that they are matured enough to be responsible for their actions. Most (83.9\%) of the sampled households had family size of between 1 and 5 withalmost $60 \%$ of the respondents earning between $10,000-\$ 50,000$. This will probably make the respondents to be able to afford proper waste management practices.

Table 1 - Socio-Economic Characteristics of the Respondents

\begin{tabular}{lll}
\hline Variable & Frequency & Percentage \\
\hline Sex & 138 & \\
Male & 316 & 30.4 \\
Female & & 69.6 \\
Marital Status & 76 & 16.7 \\
Single & 368 & 81.1 \\
Married & 7 & 1.5 \\
Widow & 3 & 0.7 \\
Separated & & \\
Occupation & 138 & 30.4 \\
Civil service & 214 & 47.1 \\
Trading & 77 & 17.0 \\
Artisan & 11 & 2.4 \\
Farming & 14 & 3.1 \\
Others & & \\
Educational level & 37 & 8.1 \\
Primary & 191 & 42.1 \\
Secondary & 211 & 46.5 \\
Tertiary & 15 & 15.0 \\
No formal education & & \\
Household size & 381 & 83.9 \\
$1-5$ & 62 & 13.7 \\
6-10 & 7 & 1.5 \\
$11-15$ & 4 & 0.9 \\
$16>$ & & \\
Income & 3 & 0.7 \\
$00.00-9,999$ & 270 & 59.5 \\
$10,000-50,000$ & 115 & 25.3 \\
$51,000-100,000$ & 43 & 9.5 \\
$101,000-150,000$ & 12 & 2.6 \\
$151,000-200,000$ & 24 & 2.4 \\
$200,000>$ & 130 & 28.6 \\
House ownership & 324 & 71.4 \\
Yes & & \\
No & & \\
\hline
\end{tabular}

Source: Field Survey, 2020.

The study showed that most $(47 \%)$ of the respondents made use of plastic bins to dispose their plastic/nylon waste, $31 \%$ of the respondents burnt their plastics/nylon waste, about $12 \%$ of the respondents disposed their plastics/nylon into nearby river. Also, about $3 \%$ 
and $2 \%$ of the respondents used sanitary landfill and composting to dispose plastics/ nylon waste respectively and the remaining $4 \%$ disposed their plastics/nylon waste using the combination of different methods of plastics/nylon disposal.

Reason for the Choice of Plastics and Nylon Disposal Methods: The study observed that $54 \%$ of the respondents' choice of plastic and nylon disposal methods was due to its time savings, about $22 \%$ of the respondents maintained that affordability influenced their choice of plastic/nylon disposal methods, $12 \%$ of the respondents indicated distance for plastic and nylon disposal method, $9.5 \%$ of the respondents showed that availability of method / means of disposal was responsible for their choice while only $3 \%$ of the total respondents employed combinations of method to get rid of wastes in their households. This implies that they employed the available disposal method convenient to use in their community.

Difficulties Experienced in Disposing off Plastic and Nylon Waste: The study showed that only few $(14 \%)$ of the respondents' encountered one difficulty or the other in disposing their plastic and nylon waste while the majority (86\%) of the respondents indicated otherwise. It can be inferred that majority of the respondents did not encounter any difficulty in disposing off their plastic and nylon waste. The study observed indiscriminate disposal all over the environment.

Expenditures on plastic and nylon disposal by the respondents in the study area revealed that majority (76\%) of the respondents spent between one naira and one thousand naira ( $\leq 1000$ ) followed by $16 \%$ those that spent between $1100-2000$, $4 \%$ of the respondents spent between $\$ 2100$ - $\$ 3000$ and above $\$ 3100$ respectively. This suggests that the respondents spent some amount of money based on the method of disposal available /chosen and the volume/ weight of waste generated.

Factors influencing plastic and nylon disposal in the study area showed that most (34\%) of the respondents opined that environmental awareness on the proper disposal of waste exposed them to the chosen disposal method, $29 \%$ of the respondents that their household size influence the choice of disposal methods, respondents' house location was another factor considered by $12 \%$ of the respondents. Also, about $6 \%$ of the respondents accounted for those whose income and house ownership respectively were influenced by the choice of disposal method employed. Some socio-economic factors such as age, marital status and educational level were also considered in choosing methods of plastic and nylon disposal by $3 \%, 5 \%$ and $1 \%$ of the respondents respectively. Two percent of the respondents considered other factors most suitable for them in choosing plastic and nylon disposal in their environment and only $1.5 \%$ of the respondent combined all factors that could influence the choice of plastic and nylon disposal in their community.

Threat posed by to the environment. It was informed by $29.5 \%$ of the respondents that, plastic and nylon waste disposal block water ways, about $22 \%$ of the respondents opined that it litters the neighborhood, $20 \%$ indicated that plastics and nylon waste forms heaps along major streets across the city, $10 \%$ declared that it causes air pollution while $7 \%$ of the respondents stated that plastics and nylon waste pose threat on human health, $10 \%$ maintained that plastics and nylon waste disposal pose many threats to the environment and only $1 \%$ affirmed that there are other threats best known to them. It can be inferred that plastic and nylon waste pose many threats to the environment.

Various methods of waste disposals examined were: compositing, disposal into the rivers and streams, plastic bins, burying and sanitary hills. These are shown in table 1 with only the significant factors at various levels.

The factors influencing disposal of plastic/nylon through compositing is significant at $1 \%$ significant level by employing waste collectors.

Disposal into the river, causing pollution, and blocking water way is influenced by house ownership at 0.05 significant level. This implies that when there is no proper dumping site to dump refuse, people dump into the rivers.

Plastic bin is another method of disposing plastic/nylon. This is influenced by secondary and tertiary education status at 0.05 significant levels respectively. Owing a house personally is influence using plastic bin for disposal and significant at 0.05 . Also employing 
waste collector influence using plastic waste dustbin for it will be easier for the collector to carry away. However sanitary landfill as method of plastic/nylon waste is insignificant at any levels. This could infer that land is not available or scarce to be dumping refuse and could result into environmental pollution.

Table 2 - Plastic/Nylon Waste Disposal

\begin{tabular}{|c|c|c|}
\hline Plastic and nylon & Frequency & Percent \\
\hline \multicolumn{3}{|c|}{ Methods of plastic and nylon disposal } \\
\hline Plastic bin & 215 & 47.4 \\
\hline Burning & 142 & 31.3 \\
\hline Disposal in river & 56 & 12.3 \\
\hline Composting & 13 & 3.0 \\
\hline Sanitary landfill & 9 & 2.0 \\
\hline Combination & 19 & 4.2 \\
\hline \multicolumn{3}{|c|}{ Reason for the choice of plastic and nylon disposal method } \\
\hline Time savings & 246 & 54.2 \\
\hline Affordability & 100 & 22.0 \\
\hline Distance & 53 & 11.7 \\
\hline Availability & 43 & 9.5 \\
\hline Combinations of any & 12 & 2.6 \\
\hline \multicolumn{3}{|c|}{ Difficulty in disposing plastic and nylon waste } \\
\hline Yes & 64 & 14.1 \\
\hline No & 390 & 85.9 \\
\hline \multicolumn{3}{|l|}{ Substitutes of plastic and nylon } \\
\hline Leaf & 159 & 34.9 \\
\hline Glass bottle & 52 & 11.4 \\
\hline Ceramics & 56 & 12.3 \\
\hline Paper & 175 & 38.5 \\
\hline Others & 12 & 2.6 \\
\hline \multicolumn{3}{|c|}{ Amount spent on plastic and nylon disposal } \\
\hline$\leq 1000$ & 345 & 76.0 \\
\hline $1100-2000$ & 73 & 16.1 \\
\hline $2100-3000$ & 19 & 4.2 \\
\hline$\geq 3100$ & 17 & 3.7 \\
\hline \multicolumn{3}{|c|}{ Factors 1 nfluencing plastic and nylon disposal } \\
\hline House ownership & 26 & 5.7 \\
\hline House location & 52 & 11.5 \\
\hline Environmental awareness & 155 & 34.1 \\
\hline Income & 29 & 6.4 \\
\hline Age & 13 & 3.0 \\
\hline Household size & 131 & 28.8 \\
\hline Educational level & 25 & 5.5 \\
\hline Marital status & 7 & 1.5 \\
\hline Combination & 7 & 1.5 \\
\hline Others & 9 & 2.0 \\
\hline \multicolumn{3}{|l|}{ Threat to the environment } \\
\hline Blocking water ways & 134 & 29.5 \\
\hline Air pollution & 47 & 10.3 \\
\hline Heaps along the street & 90 & 19.8 \\
\hline Health implication & 32 & 7.0 \\
\hline Littering the neighborhood & 101 & 22.2 \\
\hline Combination & 45 & 9.9 \\
\hline Others & 5 & 1.1 \\
\hline
\end{tabular}

Source: Field Survey, 2020.

The likelihood-ratio test for the overall model is shown in table 2. This measure tests the null hypothesis that all coefficients in the logistic model are 0 . Because the observed significance level is small (0.000), the null hypothesis can be rejected. Therefore, it is concluded that the final model is significantly better than the "intercept-only' model.

The variation in the values of the dependent variable that is explained by the independent variables cannot be measured directly in logistic regression models, as it can be in multiple linear regression ones with $R^{2}$. However, the pseudo $r^{2}$ statistics can provide an indication of explained variation in the values of the dependent variable, similar to the $R^{2}$ in multiple linear regression models. These approximations are presented in table 3. Larger pseudo r-square statistics indicate that more of the variation in the values of the dependent variable is explained by the model, to a maximum of 1 . The Cox and Snell $R^{2}(45 \%)$ and the 
Negelkerke $R^{2}(23 \%)$ are large enough. The Negelkerke $R^{2}$ indicates that $49 \%$ of the variation in the factors influencing plastic/nylon disposal is explained by the model. This percentage is satisfactory as the values of logistic regression measures are almost always much smaller than the corresponding ones for a linear model (Norusis, 2005).

The null hypothesis that the model adequately fits the data can be examined by the Pearson and Deviance tests in the Goodness-of-fit part of table 4. Because the significance level is much greater than 0.05 , the null hypothesis that the model does not adequately fit the data is rejected.

Table 3 - Factors influencing plastic/nylon waste disposal methods

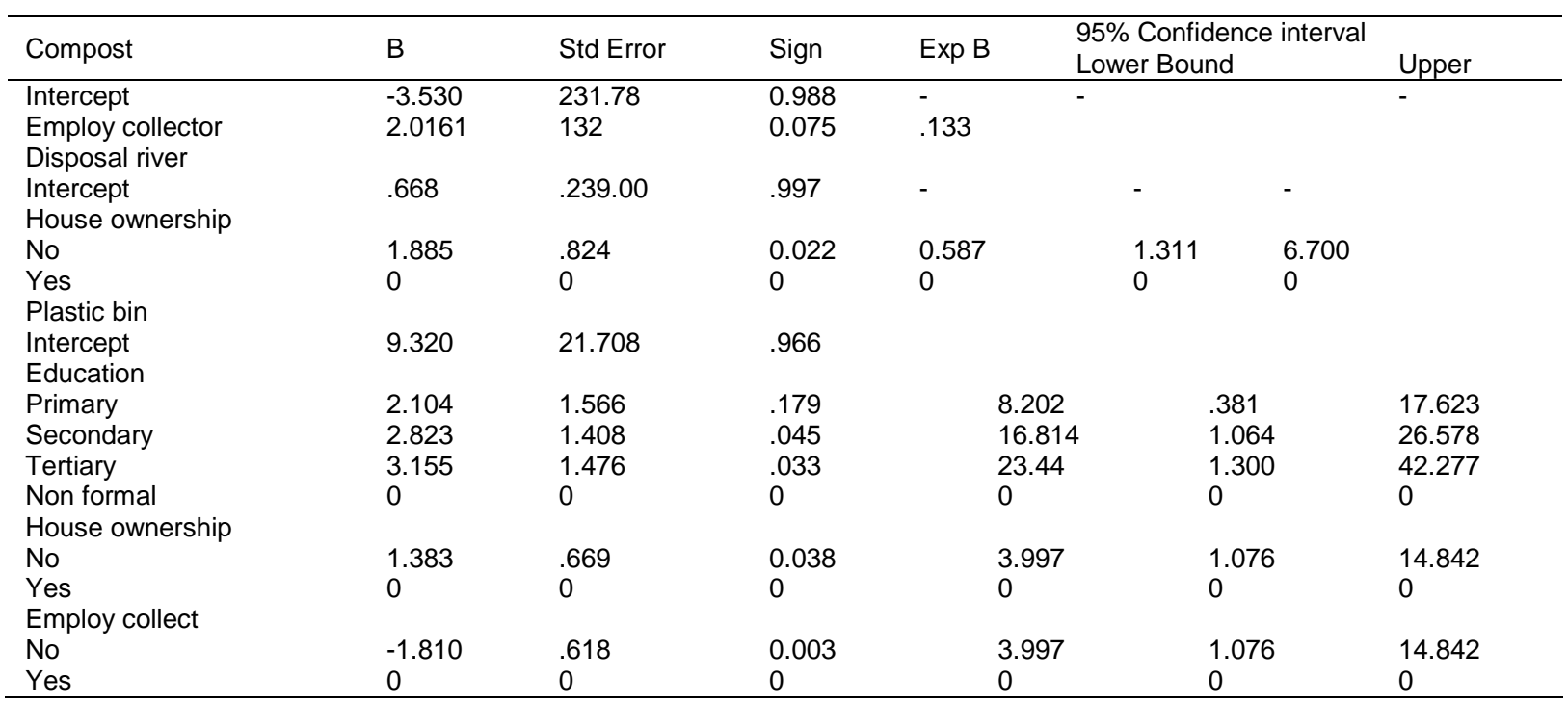

Source: Field survey, 2020.

Table 4 - Model Fitting Information

\begin{tabular}{llll}
\hline Model & Model Fitting Criteria & \multicolumn{2}{l}{ Likelihood Ratio Tests } \\
& -2 Log Likelihood & Chi-Square & Df \\
\hline Intercept Only & 944.797 & 276.362 & Sig. \\
Final & 668.435 & 276.362 & 115 \\
\hline
\end{tabular}

Table 5 - Pseudo R-Square

\begin{tabular}{lc}
\hline Cox and Snell & .456 \\
Nagelkerke & .494 \\
McFadden & .236 \\
\hline
\end{tabular}

Source: Field Survey, 2020.

Table 6 - Goodness-of-Fit

\begin{tabular}{llll}
\hline & Chic square & DF & Sig \\
Pearson & 1123.525 & 1055 & 0.07 \\
Deviance & 563.566 & 1055 & 1.000 \\
\hline
\end{tabular}

Source: Field Survey, 2020.

\section{CONCLUSION}

The study discovered lots of littering of plastics /nylon in Oyo state, causing sanitation problems. Mixed plastic making up a large proportion of the litter: Nylon store bags, nylon water bags and plastic water/beverage bottles. The study found that most of the respondents disposing and using plastic/nylons were females and married. Many of them were educated which supposed to inform proper waste management practices. Different socioeconomic characteristic were regressed to known factors influencing plastic/nylon disposal methods. Various methods of waste disposals examined were compositing, disposal into the rivers, plastic bins, burying and sanitary hills. Plastic bin method of disposing plastic/nylon was 
found influenced significantly by secondary and tertiary education status and ownership of the house. This study indicates high household consumption of plastic/nylon and socioeconomic factors influencing methods of disposal.

\section{RECOMMENDATIONS}

- More awareness should be made about plastic/nylon pollution and proper disposal;

- It is therefore recommended that alternative packaging materials and reuse of plastic/nylon should be encouraged due to the difficulty in disposal. This other packaging materials should biodegradable;

- There is a need to make nylon/plastic materials expensive or scarce by discouraging its production in other to discourage it usage;

- Also, there should be intense advocacy on the threats nylon/plastics improper disposal causes on the environment.

\section{REFERENCES}

1. Adedugbe, A. (2017). Remove, Reduce, and Recycle - The Waste Nylon Sachet Water in Nigeria. In: Association of African Entrepreneurs. Available on: https://aaeafrica.org/

2. Ademola, A.O. Oyesola, O.B. Osewa, S.O. (2012). Assessment of shea butter processing among rural dwellers in Atisbo local government area of Oyo state, Nigeria. European Journal of Business and Social Sciences, Vol.1 (6), p 1-8. Available on http://www.ejbss.com/recent.aspx.

3. Alade, B. (2017). Plastic packaging contributes to economic development. In: The Guardian Business. Available on: https://guardian.ng

4. Babatunde, A. and Biala, I. (2010) 'Externality Effects of Sachet Water Consumption and the Choice of Policy Instruments in Nigeria: Evidence from Kwara State', J Economics, 1(2), pp. 113-131.

5. Delaney, P. (2013). How Long it Takes for Some Everyday Items to Decompose. In: Ecoaware General. Available on https://www.down2earthmaterials.ie/

6. Earth Day, (2018). End plastic pollution. Facts Sheet: Plastics in the ocean. Available on: https://www.earthday.org/fact-sheet-plastics-in-the-ocean/

7. Hammed T.B., Soyingbe A.A., Adewole D.O. (2011). An abattoir waste water management through composting: A case study of Alesinloye waste recycling complex. International Journal of Interdisciplinary Social Sciences, 6(2): 67-78.

8. Ibrahim, F.K., Kolo, B.S.,Fulata, A.M., Adam, S. (2020). The Environmental effects of dumped sachet (Polyethene) water on soil. International Journal of Scientific and Engineering Research. Vol. 11 (Issue 1): 624.

9. Kadafa, A.A1, Ayuba, H.K1 and Idris N.M1 Mixed Plastic Waste As An Intractable Environmental Problem In Abuja, Nigeria. International Journal of Science, Environment and Technology. ISSN 2278-3687 Vol. 6, No 2, 2017, $971-979$.

10. Kehinde,O., Ramonu, O.J., K.O. Babaremu, K.O., Justin, L.D.(2020). Plastic wastes: environmental hazard and instrument for wealth creation in Nigeria, Heliyon, Volume 6, Issue 10. ISSN 2405 8440. Available on https://doi.org/10.1016/j.heliyon.2020.e05131.

Livni, E. (2019). The Climate Economy. In: On World Oceans Day, the seas are awash in plastic pollution. Available on: https://qz.com

11. Norusis M.J. (2005). SPSS14.0 Advanced Statistical procedures companion, upper saddle river, NJ Prentices, PP 92.

12. NPC. (2012). National Population Commission Nigeria. Retrieved from www.population.gov.ng. Accessed 16th April 2012.

13. Obayelu, A.E (2013). Economic and Environmental Effects of Solid Waste Management in Ibadan Metropolis of Oyo State, Nigeria. Journal of Environmental Conservation Research, Volume 1(2):21-28. DOI: 10.12966/jecr.08.02.2013.

14. Sridhar, M. K. C. and Hammed, T. B. (2014). Turning Waste to Wealth in Nigeria: An Overview. Journal of Human Ecology, Volume 46(2): 195-203. 